\title{
Building an Environmental Regime in the Yellow Sea Sphere
}

Kyung-Keun Cho

(Kyungsung University)

\section{Contents}

I . Introduction

II. Conditions of the Yellow Sea sphere

III. Lessons of major marine regimes
IV. Alternative proposal for policy

V. Conclusion

- Keywords: international regime, the Yellow Sea, international environmental politics, the Bohai Bay, marine pollution

\section{【 ABSTRACT 】}

The purpose of this essay is to suggest a scheme for the environmental cooperation in the Yellow Sea Environmental Sphere (YSES). For this purpose, it uses both the international regime theory and three appropriate cooperation cases: the SEAPOL regime, the Mediterranean Sea regime, and the North Sea regime. Based on the theory and cases, this paper suggests the MOSS approach in the Bohai Bay: its main project is the BoCP, and its supplementary projects are the ICCM, the EDCM, and the KBCM. Those projects will be managed by the YSEMM. Nevertheless, it is still controversial if the cooperation in the Bohai Bay can be smoothly evolved into the YSES regime. Therefore, for the successful regime evolution, South Korea and international organizations should motivate China with incentives like the support for the Bohai Bay. 


\section{I . Introduction}

Despite some flaws, the international regime theory is still one of the most persuasive approaches not only in explaining how and why nations cooperate, especially in the issue-area of environment, but also in initiating and promoting such cooperations. This is why most scholars have adopted this perspective in analyzing international environmental cooperations and molding new ones: the co-work by Edward L. Miles, Arild Underdal and Jorgen Wettestad and that by Volker Rittberger, Jonathan Michie and John G. Smith are prominent examples of the former,1) while the co-work by Mark J. Valencia and his colleagues is that of the latter.2)

To link the regime theory to the establishment as well as the development of an environmental cooperation, scholars are using real environmental cooperation cases in addition to theoretical findings. Likewise, this paper uses both three appropriate cases and useful theoretical findings to suggest a scheme for the environmental cooperation in the Yellow Sea sphere, the purpose of this paper.

The three cases are the SEAPOL regime, the Mediterranean Sea regime, and the North Sea regime. The SEAPOL regime is important for the Yellow Sea since its success is unique in the Asia-Pacific region. The Mediterranean Sea regime is selected because it has been a textbook for other marine regimes. Finally, the reference to the North Sea regime is due to its high efficiency.

Although this study is policy-oriented, it discusses the theoretical findings to suggest detailed guidelines and policy options for the Yellow Sea regime. Three important premises underlie this study. The first one is the international regime theorists' common assumption that cooperation occurs despite international anarchy. It shares the neo-liberalists' thought that cooperation results from the pursuit of self-interest: this means that "egoistic self-interest is an important determinant of regime." 3 )

The second assumption is that "shared knowledged is a necessary condition of regime formation, and transnational scientific contacts may help bring this about."4) As Peter M. Haas points out, 'epistemic communities' serve to establish shared knowledge and to spread

1) Miles, Edward L., Arild Underdal and Jorgen Wettestad, Environmental Regime Effectives: Confronting Theory with Evidence (Cambridge: MIT Press, 2001); Rittberger, Volker, Jonathan Michie and John G. Smith, Regime Theory and International Relations (Oxford: Oxford University Press, 1995).

2) Valencia, Mark J. (ed), Maritime Regime Building: Lessons Learned and Their Relevance for Northeast Asia (The Hague/Boston/London: Martinus Nijhoff Publishers, 2001).

3) Krasner, Stephen D., "Structural causes and regime consequences: regimes as intervening variables," in Stephen D, Krasner (ed.), International Regimes (Ithaca and London: Cornell University Press, 1983), p. 12; see also, for example, Keohane, Robert O., "The demand for international regimes," in Krasner(1983), p. 154.

4) List, Martin and Volker Rittberger, "Regime Theory and International Environment Management," in Andrew Hurrell and Benedict Kingsbury (ed.), The International Politics of the Environment: Actors, Interests, and Institutions (Oxford: Oxford University Press, 1992), p. 103. 
it in decision-making circles.5) Accordingly, this study assumes that having 'epistemic communities' is a requisite for regimes, contending that "for all practical purposes, adequate knowledge about the problem itself and available response options is a necessary condition for designing and operating effective international regimes."6)

The final one is that once a regime is established, often has its own influence on nations and thus facilitate's more cooperation among them. This assumption is compatible with functionalists' assumption that "although governments usually cooperate in specific issue areas, this 'functional' cooperation can extend to other areas, leading to a growing sense of community among cooperating states."7) This accounts for evolution of regime in its scope and strength. To explain this evolution, Stephen D. Krasner suggests four feedback mechanisms from established regimes to basic causal variables: first, regimes may alter actors' calculations of how to maximize their interests; second, regimes may alter interests themselves; third, regimes may become a source of power to which actors can appeal; and fourth, regimes may alter the power capabilities of different actors, including states.8)

These premises, especially the first and the third ones, suggest that 'interest' is the utmost factor in forming and developing regimes. Therefore, how to promote states' common interests and diminish their conflicts is the most important task in framing policy options for environmental cooperation in the Yellow Sea sphere.

This paper first describes the current situation of the Yellow Sea sphere to explain the necessity of an environmental regime. Next, it briefly describes the three marine cooperations and analyze their evolutions toward regimes. Last, it introduces policy options to build a regime in the Yellow Sea sphere.

\section{ПI. Conditions of the Yellow Sea sphere}

The Yellow Sea, a semi-enclosed water area surrounded by China and the Korean peninsula, has suffered most from pollution. For both Korea and China have developed industrial facilities along their coastal rims facing this sea, the coastal water on both sides became contaminated by industrial wastewater and domestic sewage, as well as the high

5) Haas, Peter M., "Introduction: Epistemic Communities and International Policy Coordination," in Knowledge, Power, and International Policy Coordination, special issue, International Organization 46 (winter 1992), pp. 1-36; Haas, Peter M., Saving the Mediterranean: The Politics of International Environmental Cooperation (New York: Columbia University Press, 1990).

6) Andresen, Steinar, Tora Skodvin, Arild Underdal and Jorgen Wettestad, Science and politics in international environmental regimes: Between integrity and involvement (Manchester and New York: Manchester University Press, 2000), p. 3.

7) Harris, Paul G., "Introduction: International Environmental Cooperation in Pacific Asia," in Paul G. Harris (ed.), International Environmenatl Cooperation: Politics and Diplomacy in Pacific Asia (Boulder, Colorado: University Press of Colorado, 2002), p. 7.

8) Krasner, Stephen D., "Regimes and the limits of realism," in Krasner(1983), p. 361. 
volume of oil spills. According to the State Oceanic Administration (SOA), a Chinese governmental office, the sea water around populous cities and industrial centers faces the heaviest pollution, causing the Yellow Sea to be the most suffered.9) It also reported that China's heavily polluted ocean areas amounted to 32,590 square $\mathrm{km}$ by the end of 2001, a rise of 4,000 square $\mathrm{km}$ over the previous year. ${ }^{10)}$ Most international environmental organizations have warned the seriousness of the Yellow Sea pollution as well. The United Nations Environment Program (UNEP), for example, concluded in its 2002 report that the pollution of the Yellow Sea was getting more serious despite the international restrictions. ${ }^{11)}$

$<$ Table $1>$ is the summary of the Yellow Sea part of the document, released by the Global International Waters Assessment (GIWA) on September 2, 2003. On the whole, freshwater shortage, habitat and community modification and unsustainable exploitation of fisheries assume the most serious aspect. In detail, modification of stream flow, pollution of existing supplies, eutrophication, loss and modification of ecosystems or ecotones, modification of ecosystems or ecotones, overexploitation of fisheries, destructive fishing practices, and other social and community impacts in sustainable exploitation of fisheries assume very serious concerns. Changes in the water table, economic impacts in freshwater shortage, chemical pollution, solid wastes, spills, economic impacts in pollution, economic and other social and community impacts in habitat and community modification, decreased viability of stock, health impacts in unsustainable exploitation of fisheries, and changes in hydrological cycle have moderate impact. In short, the rating shows that the pollution level of the Yellow Sea is severe and increasing.

Korea, worrying that it will suffer the most from the contamination of the Yellow Sea sphere, has been trying to find diversified antipollution measures and plans. The Korean government signed the reciprocal Korea-China Environmental Cooperation Agreement in October 1993 and organized the Korea-China Environmental Cooperation Committee. It has also been carrying out many multilateral cooperation plans such as the Northwest Pacific Action Plan (NOWPAP). The Korean government's efforts stand high in public estimation in the respect that its multilateral environmental cooperation, begun only 10 years ago, deals with almost every major issue. However, the efforts by the Korean government have been criticized as being too abstract and unorganized.

The Chinese government, encouraged by the good records of the ninth Five-year Plan (the 9.5 Plan), launched the tenth Five-year Plan (the 10.5 Plan) in December 2001, which included measures to handle with marine pollution. ${ }^{12)}$ Concerning the marine pollution, China

9) China Daily (2002. 3. 30).

10) China Daily (2002. 4. 1).

11) UNEP, Global Environment Outlook 3: Past, present and future perspectives (Sterling, VA: Earthscan Publications Ltd, 2002), p. 192.

12) The Chinese government announced that during the 9.5 plan the discharging volume of main pollutants had been reduced by 10 percent and China had banned and shut down more than 84,000 small enterprises which produced severe pollutants with no hope to be harnessed. It also reported that over 90 percent of industrial enterprises reached the standard for main pollutants discharging during the period. (http://english.peopledaily.com.cr/200201/28/eng2002012889496.shtml)(2003. 10. 
is now paying special attention to the Bohai Bay, a part of the Yellow Sea and the most contaminated area among the sea waters of China. For instance, the Bohai Project, one of the most laborious anti-pollution projects of China, has been strongly backed up by the Chinese Government financially and administratively for a good chance of success. ${ }^{13)}$ Despite these endeavors, there are three reasons why it is yet unrealistic to assure that China has done and will make a success of its environment policy: first, the reliability of statistics of Chinese government is still low; second, these environmental measures might be adjuncts to Chinese industrial development in the east coast; and finally, China runs short of funds and technologies to realize its environmental goal.

〈Table 1〉 Yellow Sea: the scores assigned to each issue, by sub-regional task teams and the predicted direction of future changes

\begin{tabular}{|c|c|c|}
\hline \multirow{6}{*}{$\begin{array}{l}\text { Freshwater } \\
\text { shortage } \\
3(\uparrow)\end{array}$} & Modification of stream flow & 3 \\
\hline & Pollution of existing supplies & 3 \\
\hline & Changes in the water table & 2 \\
\hline & Economic impacts & 2 \\
\hline & Health impacts & 1 \\
\hline & Other social and community impacts & 1 \\
\hline \multirow{11}{*}{$\begin{array}{c}\text { Pollution } \\
2(\uparrow)\end{array}$} & Microbiological & 1 \\
\hline & Eutrophication & 3 \\
\hline & Chemical & 2 \\
\hline & Suspended solids & 1 \\
\hline & Solid wastes & 2 \\
\hline & Thermal & 1 \\
\hline & Radionuclides & 0 \\
\hline & Spills & 2 \\
\hline & Economic impacts & 2 \\
\hline & Health impacts & 1 \\
\hline & Other social and community impacts & 1 \\
\hline \multirow{5}{*}{$\begin{array}{l}\text { Habitat and } \\
\text { community } \\
\text { modification } \\
3(\uparrow)\end{array}$} & Loss of ecosystems or ecotones & 3 \\
\hline & Modification of ecosystems or ecotones & 3 \\
\hline & Economic impacts & 2 \\
\hline & Health impacts & 0 \\
\hline & Other social and community impacts & 2 \\
\hline
\end{tabular}

17).

13) Environment Minister Xie Zhenhua said that pollution levels remained unacceptably high in the Bohai Sea and that he would take a special interest in the Bohai Sea pollution in order to meet the environmental protection standard. (http://www.usembassy-china.org.cn/sandt/estnews0615.htm) (2003. 10. 17). 


\begin{tabular}{|c|c|c|}
\hline \multirow{8}{*}{$\begin{array}{l}\text { Unsustainable } \\
\text { exploitation } \\
\text { of fisheries } \\
3(\uparrow)\end{array}$} & Overexploitation of fisheries & 3 \\
\hline & Excessive bycatch and discards & 1 \\
\hline & Destructive fishing practices & 3 \\
\hline & Decreased viability of stock & 2 \\
\hline & Impact on biological and genetic diversity & 1 \\
\hline & Economic impacts & 3 \\
\hline & Health impacts & 2 \\
\hline & Other social and community impacts & 3 \\
\hline \multirow{7}{*}{$\begin{array}{l}\text { Global } \\
\text { Change } \\
1(\uparrow)\end{array}$} & Changes in hydrological cycle & 2 \\
\hline & Sea level change & 1 \\
\hline & Increased UV-B radiation & 0 \\
\hline & Changes in ocean $\mathrm{CO} 2$ sources/sink function & 0 \\
\hline & Economic impacts & 1 \\
\hline & Health impacts & 1 \\
\hline & Other social and community impacts & 1 \\
\hline
\end{tabular}

* Present situation : 0 No known impact

1 Slight impact

2 Moderate impact

3 Severe impact

* Likely direction of future changes for environment impact

$\uparrow$ Increased impact

$\rightarrow$ No changes

$\downarrow$ Decreased impact

* Source: the Global International Waters Assessment (GIWA)

(http://www.giwa.net/giwa_doc/giwa_matrix.pdf)(2003.10. 17)

North Korea, who shares the Yellow Sea, seems to have few governmental will and capacity to confront the pollution yet.

Therefore, if South Korean government wants to effectively initiate a grand design for environmental restoration and conservation in the Yellow Sea, it ought to approach this issue by strategically choosing what it can do, what is the most effective, and toward what China and North Korea will take a positive attitude.

\section{Lessons of major marine regimes}

\section{The SEAPOL regime}

The Southeast Asian Programme in Ocean Law, Policy and Management (SEAPOL) is a non-governmental network of high level scholars, government officials, and private individuals with a professional interest primarily in ocean affairs of the Southeast Asian 
and APEC regions. SEAPOL aims to facilitate the exchange of information and ideas related to current ocean law, policy and management in the region and to promote regional and sub-regional cooperation among national governments as well as among public and private institutions in ocean affairs. It promotes the exchanges through networking, sponsored research, training programs, consultants, seminars, and national, regional and international forums.

SEAPOL was inaugurated in 1981 by the proposal of the International Development Research Centre (IDRC) from Canada. Since Canadian International Development Agency (CIDA) took the supporting role in place of the International Development Agency, SEAPOL has developed into various kinds of networks. The networks take place among people, among institutes, within a field and among fields, within a government and among governments, within an area and among areas, within a society and among societies. ${ }^{14)}$

Four factors helped this process develop: motivating academic experts from developing countries to develop constructive relations with officials of their own and neighboring countries; making the necessary information accessible to them; promoting developing countries to publish, preserve, and upgrade academic and technical documents; and finally, providing the organizers independence from their governments when holding meetings and building networks at various levels.

Until the mid-1990s, SEAPOL did not consider building a regime because it placed its identity in network-building. Nevertheless, since then, the ASEAN nations began to take interest in building a regime, endeavoring to make a feasible plan rather than a far-reaching regime that is too huge and costly. ${ }^{15}$ ) This is why they began the Gulf of Thailand Project as a part of the SEAPOL IV Project in 1996-2001, funded by CIDA. The Gulf of Thailand is a half-closed sea adjoining Cambodia, Malaysia, Thailand, and Vietnam. The project, also called MOSS (Management of Sub-Regional Seas) approach, has been rewarding. ${ }^{16)}$

Like Southeast Asia, Northeast Asia is huge: its seas comprise the Yellow Sea, the East China Sea, the East Sea, and the Sea of Okhotsk. Therefore, to win the cooperation that leads to a regime, Northeast Asia should take the MOSS Approach as in the Gulf of Thailand Project.

SEAPOL has also had a dual regime-building process. It is a strategy to promote open and unrestrained discussions among non-governmental experts and to simultaneously establish a mechanism among the leading governmental officials. By doing so, academic experts, scientists, and representatives of private organizations could openly discuss current issues, and government officials could have the off the record opportunity to discuss issues that could not be cleared up in an official meeting.

This 'two tracks strategy,' however, had some defects. The discussions among the non-governmental experts tended to incline toward science. The off the record discussions

14) Johnston, Douglas M., "Southeast Asia: Lessons Learned," in Valencia(2001), pp. 74-75.

15) Member states of SEAPOL now are Brunei, Cambodia, Indonesia, Laos, Malaysia, Myanmar, the Philippines, Singapore, Thailand, and Vietnam.

16) Johnston (2001), p. 77, 78. 
among the leading officials were criticized by a group of NGOs for being exclusive and losing their contacts. These defects should be made up for.

\section{The Mediterranean Sea regime}

In 1975, the Mediterranean Action Plan (MAP) was adopted as the UNE's first 'Regional Sea Programme.'17) Since then, regional cooperation has evolved into a complex regime addressing broader environment and development issues, with a growing emphasis on integrated coastal area management. ${ }^{18)}$ Especially, during the period of MAP Phase II (1996-2005), its focus has evolved from the narrow confines of pollution issues to broader environment and development concerns consistent with the spirit of Rio. ${ }^{19)}$

The Mediterranean Sea regime was based upon the Barcelona Convention, which was adopted in 1976 and has been in force since February 1978.20) The protocols of the MAP in 1976 were related to the elimination of pollution by dumping from ships and aircraft and by oil spill. The protocols in 1980 concerned the protection of the Mediterranean Sea from land-based sources of pollution, prohibition against commonly used highly toxic chemical compounds and joint control on a series of lead toxic substances. The protocols in 1982 stipulated specially preserved areas, and in 1985, a plan to control 12 pollutants and a group of pollutants was adopted. These protocols required contracting parties to report how they performed their legal duties, and this requirement consequently contributed to the strengthening of the regime by promoting the regional countries' responsibility and participation.

Since 1976, under the auspices of the UNEP, the MAP has been active in researching, monitoring, training hundreds of scientists in Northern Africa, and providing them with new experiment equipments. In addition, The MAP initiated many plans for the regional environmental cooperation: in 1976, it established the Regional Oil Combating Center (ROCC), which later became the REMPEC (Regional Marine Pollution Emergency Response Center for the Mediterranean Sea), under the control of the IMO (International Maritime Organization) and funded by the Mediterranean Trust Fund in Malta; in 1977, the Integrated Planning Committee (the Blue Plan) to promote an economic plan on a broader point of view; in 1979, the Priority Action Plan in Yugoslavia to study conflicting interests of developing countries; in 1982, the Regional Meditation Committee in Athens; in 1985, the Center for Problems of Special Preservation Area in Tunisia; and in 1990,

17) This MAP is actually MAP Phase I. For MAP Phase I, see UNEP(1975).

18) Chircop, Aldo, "The Mediterranean: Lessons Learned." in Valencia (2001), p. 27.

19) Chircop (2001), p. 27.

20) The countries which signed the Barcelona Convention are Albania, Algeria, Bosnia and Herzegovina, Croatia, Cyprus, Egypt, France, Greece, Israel, Italy, Lebanon, Libya, Malta, Monaco, Morocco, Slovenia, Spain, Syria, Tunisia, Turkey and the European Union, and the Athens-based MAP Coordinating Unit (MEDU) under the auspices of the UNEP is the Secretariat of the MAP. 
the Program of the Coastal Area Management to form a plan suitable for regional environmental conditions.

Especially for researching and monitoring, the Coordinated Pollution and Monitoring Programme in the Mediterranean (MEDPOL) was conceptualized. MEDPOL has operated in three phases: Phase I (1975-1980) focused on research; Phased II (1981-1995) concentrated on monitoring;21) MEDPOL Phase III (1996-2005) has focused on the scientific and technical aspects of implementing legal responsibilities, management measures in the combating of pollution from land-based activities and sources, and the Coastal Area Management Programme (CAMP), while continuing monitoring.22)

Although the MAP was originally a regime to sort out and control pollutants in the Mediterranean area, it developed into a regime to have overall control of the area. Consequently, despite the Mediterranean area saw the growth of industry and population by double during the last 20 years, pollution level has not changed much.

As Peter M. Haas well analyzed, researching (focus of Phase I of the MEDPOL, 1975-1980) and monitoring (focus of Phase II of the MEDPOL, 1981-1995) were successful due to the development and function of 'epistemic communities.'23) In developing the Mediterranean Sea regime, knowledge-building activities including scientific groundwork, the expansion of not only the official participation of NGOs, but also that of the public, guaranteed by the MAP Phase II and the amended Barcelona Convention, have played a crucial role.

Since the Mediterranean area belongs to different legal regimes even regarding the same issue, sense of attachment has been a prerequisite for regional cooperation. Hence, the Mediterranean regime has emphasized homogeneousness while respecting cultural and political diversity.

\section{The North Sea regime}

International cooperation to combat against marine pollution in the North Sea and the Northeast Atlantic was stimulated by the Convention for the Prevention of Marine Pollution by Dumping from Ships and Aircraft (the Oslo Convention) and the Convention for the Prevention of Marine Pollution from Land-based Sources (the Paris Convention). ${ }^{24)}$ The former, signed by Belgium, Denmark, Finland, France, Germany, Iceland, Ireland, the Netherlands, Norway, Portugal, Spain, Sweden, and the UK in 1972, entered into force in 1974. The latter, opened for signature in June 1974 with a new member, the EU, in place of Finland, entered into force in 1978.

The Oslo Convention had the black/gray annex system. Annex I (black list) listed the

21) For MEDPOL Phase I, see UNEP(1984) and UNEP/MAP(1986), and for MEDPOL Phase II, see UNEP/MAP/FAO(1986).

22) See UNEP(1995).

23) See Haas(1990).

24) Andresen, Steinar, "The North Sea and Beyond: Lessons Learned," in Valencia(2001), p. 42. 
substances prohibited from dumping, Annex II (gray list) listed the substances requiring a specific permit from the authorities for dumping, Annex III listed the substances requiring a specific permit from the appropriate authority in each case for dumping, and Annex IV dealt with incineration in the sea. ${ }^{25)}$ For the Convention, the Oslo Commission (OSCOM) was established with the members' representatives. Member countries had a duty to keep the records of the materials dumped, including its date, place and method, and to transmit them to the Commission upon request. The OSCOM's duties are as follows: to exercise overall supervision over the implementation of this Convention; to receive and examine the records of the dumping permits; to review the condition of the seas, the efficacy of the control measures adopted, and the need for any additional or different measures; to review the contents of the Annexes to this Convention and to recommend such amendments; to discharge other functions as may be appropriate under the terms of this Convention.

The Paris Commission regulated and controlled inputs of land-based polluting sources to the sea (via the atmosphere, rivers, or direct discharges) and those from offshore platforms. The Commission was involved in a thorough review of the use and manufacture of various substances in order to establish the best environmental practice and the best available techniques to prevent pollution. It also embarked on a series of measures to protect against high levels of nutrients, which was linked to the occurrence of abnormal algal blooms. The Paris Convention also had the black/gray annex system, and each member had a duty to eliminate the substances of the black list and to reduce the substances of the gray list: each member should report what it did administratively and legislatively to the Commission, and the Commission should report what members did to each member. Because of these endeavors, dumping of industrial wastes and sewage sludge and incineration has been gradually phased out in the North Sea.

The two Conventions are under the auspices of various science/technical organizations including the Standing Advisory Committee for Scientific Advice (SACSA), the Technical Working Group, the Joint Monitoring Group (JMG). These also include North Sea Ministerial Conference, requested by Germany in early 1980s, held its first meeting in 1984 under the name of the International North Sea Conference. This Conference has held meetings in 1987, 1990,1995, 2002, and obtained good results such as reduction of dumping wasted in the North Sea by $50 \%$ regarding the land-based pollution sources at the London Conference in 1987.26) During the process, leadership of Germany played an important role, and so did the factors of the consented knowledge and the publics, which asked immediate measures against the serious effects of pollution.

The Oslo and Paris Convention for the Protection of the Marine Environment of the

25) Substances considered most harmful to the environment are included on a 'Black List,' and substances considered less harmful are included on a 'Grey List.' Caldwell, Lynton Keith, International Environmental Policy: Emergence and Dimensions, second edition (Durham and London: Duke University Press, 1990), p. 145.

26) Andresen (2001), p. 55 . 
North-East Atlantic (the OSPAR Convention) was adopted by countries bordering the Northeastern Atlantic Sea and EC Committee in 1992 replacing the earlier Oslo and Paris Conventions, and went into force in 1998. The OSPAR Convention codified the contents of the previous Conventions and included new articles of a principle of prevention and an application of the Best Available Technology (BAT) and the Best Available Practices (BAP). The OSPAR Convention abolished the black/gray system and restricted all the pollutants. The new restriction, with a few exceptions, includes low and medium radioactive contaminants and makes it clear that the decisions of the Oslo Committee carry legal binding force. The Committee meets regularly to manage the function and efficiency of the new Convention.

The North Sea regime could promote efficiency by matching hard legal regime with soft political regime. It has not only tightened legal control by the Oslo Convention but also made a political approach by ministerial joint declaration at the North Sea Conference. Three mechanisms have been important measures to promote efficiency in the North Sea regime: first, to improve report process to promote transparency; second, to adopt the differential obligation system that makes the rules less strict for a specific country or spares more time to accomplish; third, to expand the number of participating countries gradually.

\section{Major guidelines in the lessons}

The guidelines in the lessons from the three sea regimes for the Yellow Sea Environmental sphere can be summarized under the nine headings:

First, the Yellow Sea sphere should not take the regional cooperation plan that includes the whole area like the NOWPAP but the MOSS Approach as in the Gulf of Thailand Project.

Second, the forming process of the regime should include Ministers of Environment. The North Sea Regime showed the effectiveness of the meetings among the highest authorities. The over-all trend of cooperation in the non-political areas between North and South Korea and friendly relationship between China and North Korea demonstrates that a tripartite meeting of the highest authorities is possible. Unlike the North Sea case, however, the strategy to match the political approach by high-level policy with legal approach of low-level is desirable.

Third, a dual regime-building process strategy of the track one plus two is also needed in the Yellow Sea case.

Fourth, knowledge-building activities ought to be promoted through the active participation of non-governmental experts and the establishment of the system of primary research and monitoring.

Fifth, the general public should have an adequate knowledge as well as easy access to knowledge and information related to the issues. There should be various networks of cooperation within a nation or among nations, including cooperation among cities, a meeting of organizations associated with traveling, a workshop of the fisheries associations, 
and a meeting of scientists.

Sixth, it is necessary for contracting parties to report regularly on how they perform their legal duties and to promote transparency in this reporting process.

Seventh, it is a prerequisite for regional countries to have sense of attachment to the regime of their region. A regime should be established and developed toward the direction of emphasizing homogeneousness while respecting cultural and political diversity.

Eighth, the differential obligation system that makes the rules less strict for a specific country is preferable.

Ninth, since environmental department is not usually primary in a government, it should devise a proper measure to be the center of attention in a government.

\section{Alternative proposal for policy}

\section{Cooperation starting from the Bohai Bay}

Regime formation in the area of Yellow Sea Environment Sphere (YSES) can have very positive influence on establishing various environmental regimes in Northeast Asia (<Figure 1>). 27) It is, however, not an easy task. China is unwilling to follow other country's lead and has the attitude that it will only cooperate as much as it needs to. North Korea gives priority to economic development, relating all kinds of cooperation to economic benefits and its security concerns. Therefore, South Korea should approach this issue by strategically choosing what we can do, what is most effective, and toward what China and North Korea would take a positive attitude. For that reason, first of all, it is necessary to consult the North Sea regime and the Gulf of Thailand Project. They not only successfully enhanced the understanding and interchanges among the member nations, but also made a substantial progress in pollution issues.

Following the MOSS approach, it will be most effective strategy to promote the Yellow Sea Environment Ministers Meeting (YSEMM) among North and South Korea and China, and to place the focus on the anti-pollution projects of one of the sub-regions, the Bohai Bay. Although the project can be accomplished within the realm of the existing environmental cooperation between South Korea and China, it is necessary and desirable to include North Korea since the goal of the project is to build and develop a regime in the area.

27) For more than 70 percent of the Yellow Sea pollution is caused by the land pollution source, it is necessary to introduce the concept of 'YSES.' Broadly, we could say that the YSES refers to all the components, geographical and societal, of the Yellow Sea, Korean Peninsula, and China that affect the ecosystem of the Yellow Sea. From the viewpoint of multilateral environmental cooperation, however, it refers to the specific issues or sub-issues of the environment for which North and South Korea and China should cooperate with each other to improve and preserve the Yellow Sea. 
One reason why focusing on the Bohai Bay is that its pollution levels remain unacceptably high as seen in the $<$ Table 2>: it is severer than the Yellow Sea $(<$ Table 1>).28) In 2000, for instance, China recorded 28 red tides in its marine areas, 13 more cases than in 1999. Among them, 7 red tides happened in the Bohai Sea, covering an area of 2,000 square kilometers, while 4 red tides happened in the Yellow Sea, covering an

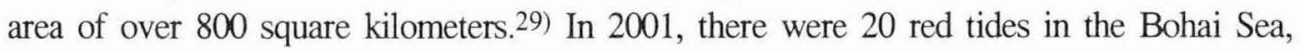
and the water quality in the offshore marine areas was mainly affected by the activated phosphate and inorganic nitrogen. The key pollutants in some marine areas include COD, oil and lead. The offshore sea water is mainly at Grade II and exceeds Grade IV. Most of the sea water exceeding Grade IV is in the East Sea, accounting for 52\%, followed by the Bohai Sea, accounting for $38.5 \%$ (cf, the Yellow Sea for $26.4 \%$ ). Compared with the previous year, the water pollution in the Bohai Sea is more serious. ${ }^{30}$ )

$\langle$ Figure 1〉 Formation of the YSES regime and its evolution

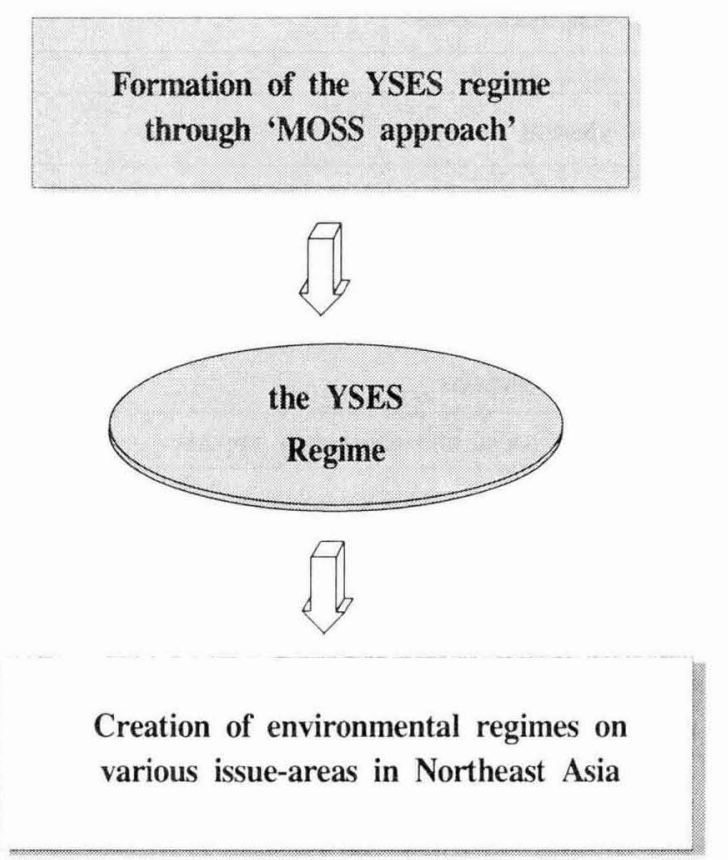

28) The Bohai Bay was estimated to be the most contaminated area among the sea waters of China. The Proportions of Super Standardized Waters increased from 26\% in 1992 to 56\% in 1996, and some parts of the bay turned out to pass the sea water standard of level IV and III. This bay was also reported to have the worst red tide: the red tide began in July 1998 spreaded up to $6300 \mathrm{Km} 2$, and another one started in September 1998 lasted over 40 days, spreading up to 5000Km2. Guan, Daoming, Gengchen Han, Juying Wang, "Marine Environmental Quality and Marine Environmental Protection in China." (http://www.unesco.or.kr/kor/science/data/Guan.doc.) (2003. 10. 17).

29) http://www.zhb.gov.c/english/SOE/soechina2000/english/marine/marine_e.htm(2003. 10. 17).

30) http://www.zhb.gov.cn/english/SOE/soechina2001/english/2-marine.htm(2003. 10. 17). 
$\langle$ Table 2〉 Bohai Sea: the scores assigned to each issue, by sub-regional task teams and the predicted direction of future changes

\begin{tabular}{|c|c|c|}
\hline \multirow{6}{*}{$\begin{array}{l}\text { Freshwater } \\
\text { shortage } \\
3(\uparrow)\end{array}$} & Modification of stream flow & 3 \\
\hline & Pollution of existing supplies & 2 \\
\hline & Changes in the water table & 3 \\
\hline & Economic impacts & 1 \\
\hline & Health impacts & 1 \\
\hline & Other social and community impacts & 1 \\
\hline \multirow{5}{*}{$\begin{array}{l}\text { Pollution } \\
2(\uparrow)\end{array}$} & Microbiological & 3 \\
\hline & Eutrophication & 3 \\
\hline & Chemical & 2 \\
\hline & Suspended solids & 1 \\
\hline & Solid wastes & 2 \\
\hline \multirow{6}{*}{$\begin{array}{l}\text { Pollution } \\
2(\uparrow)\end{array}$} & Thermal & 1 \\
\hline & Radionuclides & 0 \\
\hline & Spills & 3 \\
\hline & Economic impacts & 2 \\
\hline & Health impacts & 1 \\
\hline & Other social and community impacts & 2 \\
\hline \multirow{5}{*}{$\begin{array}{l}\text { Habitat and } \\
\text { community } \\
\text { modification } \\
3(\uparrow)\end{array}$} & Loss of ecosystems or ecotones & 2 \\
\hline & Modification of ecosystems or ecotones & 3 \\
\hline & Economic impacts & 3 \\
\hline & Health impacts & 0 \\
\hline & Other social and community impacts & 3 \\
\hline \multirow{8}{*}{$\begin{array}{l}\text { Unsustainable } \\
\text { exploitation } \\
\text { of fisheries } \\
3\end{array}$} & Overexploitation of fisheries & 3 \\
\hline & Excessive bycatch and discards & 3 \\
\hline & Destructive fishing practices & 3 \\
\hline & Decreased viability of stock & 2 \\
\hline & Impact on biological and genetic diversity & 3 \\
\hline & Economic impacts & 3 \\
\hline & Health impacts & 2 \\
\hline & Other social and community impacts & 3 \\
\hline
\end{tabular}




\begin{tabular}{c|l|c}
\hline \multirow{4}{*}{\begin{tabular}{c|} 
Global \\
Change \\
$1(\uparrow)$
\end{tabular}} & Changes in hydrological cycle & 1 \\
\cline { 2 - 3 } & Sea level change & 1 \\
\cline { 2 - 3 } & Increased UV-B radiation & 0 \\
\hline Changes in ocean CO2 sources/sink function & 3 \\
\cline { 2 - 3 } & Economic impacts & 1 \\
\cline { 2 - 3 } & Health impacts & 2 \\
\hline
\end{tabular}

* Present situation

0 No known impact

1 Slight impact

2 Moderate impact

3 Severe impact

* Likely direction of future changes for environment impact

$\uparrow \quad$ Increased impact

$\rightarrow$ No changes

$\downarrow$ Decreased impact

* Source: the Global International Waters Assessment (GIWA)

(http://www.giwa.net/giwa_doc/giwa_matrix.pdf)(2003. 10. 17)

South Korea should focus on the Bohai Bay also because Chinese governments, both at central and local level, are paying special attention to it. The Bohai Project is a part of the '33211 Project,' the most laborious anti-pollution projects of China, and is strongly backed up by the Chinese central government financially and administratively. Chinese Environment Minister Xie Zhenhua announced that pollution levels remained unacceptably high in the Bohai Sea and thus he would take a special interest in the Bohai Sea pollution in order to meet the environmental protection standard. ${ }^{31)}$ In addition, the China's Agenda 21, adopted to keep up with the Agenda 21 of the Rio Environment Conference, reflects China's concern on the Bohai Bay very well. ${ }^{32)}$ The 10.5 Plan also defines the goal for the Bohai Sea: total discharge of chemical oxygen demand (COD) into water bodies will be reduced to 1.026 million tons by 2005, and nitrogen and phosphorus to 130,000 tons and 10,000 tons respectively. For this, China has pursued the 'Clean Sea Action Plan of the Bohai Sea. ${ }^{33)}$ The State Environmental Protection Administration of China has

31) http://216.2 39.33.100/search?q=cache:v4pyK1VALRcC:www.usembassy-china.org.cn/english/sandt /estnews0615.htm+bohai+bay+environment+200l\&hl=en\&ie=UTF-8)(2002. 10. 23).

32) Of Priority Programme for China's Agenda 21, there is Remote Sensing Monitoring on Coastal Urbanization and The Environment under the Priority 5 (It is based on programme area $2 \mathrm{~A}$ of China's Agenda 21 and related to programme areas 17A, 17B and 17C). For the part related to the Bohai Bay, see http://www.acca21.org.cn/pp 5-8.htl m(2002. 10. 23).

33) In October 2001, the State Council ratified the Clean Sea Action Plan of the Bohai Sea. It is planned that 15 years will be devoted to improve the environmental quality the in Bohai Sea areas significantly and improve the eco-system preliminarily. (http://www.zh b.gov.cn/english/SOE/soechina 
alreadystarted the Bohai Action Plan focused on the Bohai Sea to strengthen the protection of environment in the Bohai Sea as well as the overall protection of marine environment. Focusing on the control of the land-based pollutants, the plan has carried out an overall project on the priority control sea area, estuaries, and pollutants.

$\langle$ Figure 2〉 The YSEMM and the YSES regime

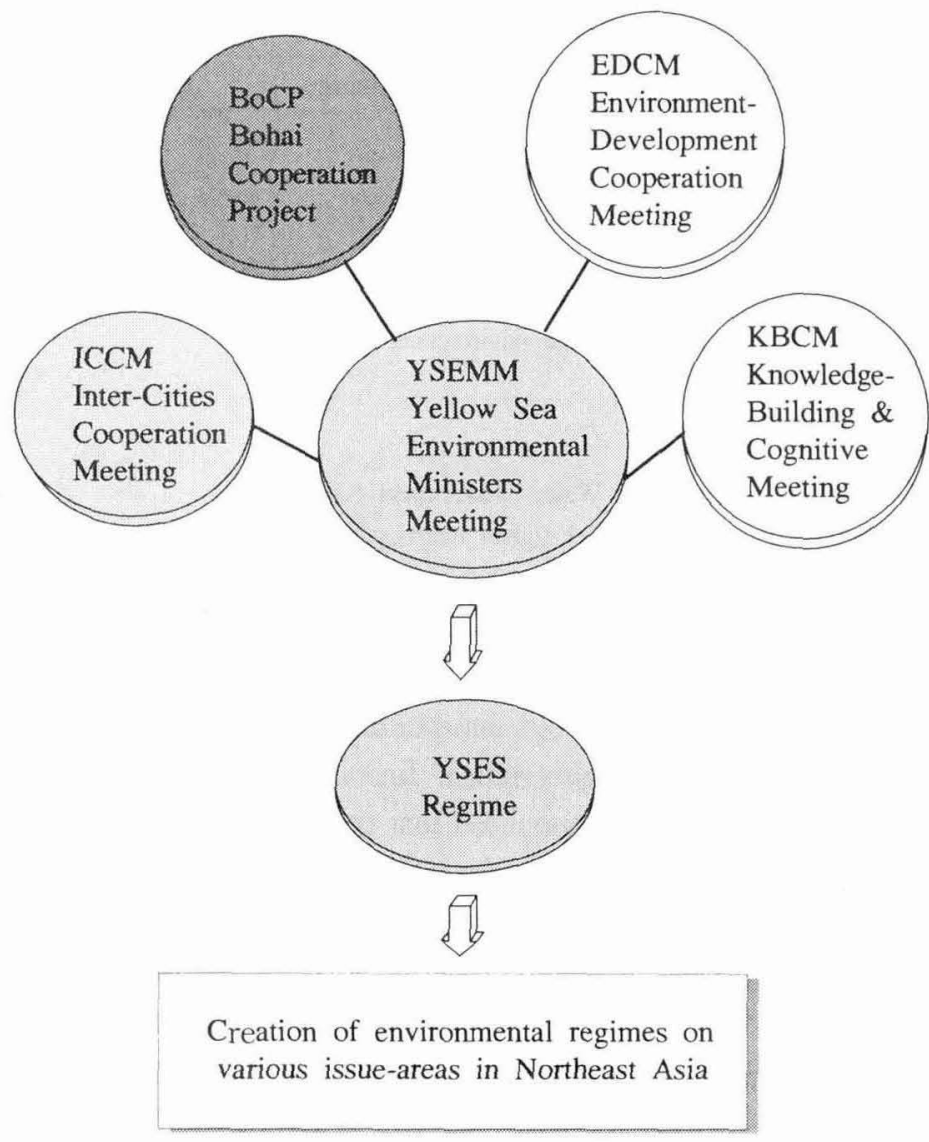

For these reasons, South Korea should initiate the Bohai Cooperation Project (BoCP) to combat against the significant pollutants. The BoCP should focus on the financial and technical support, and considering the actual necessity for reduction in pollution, China's needs (or allurement factor), and our risk, the main issues of the project would be support for a research of human and knowledge resources necessary for building a sewage treatment plant, and technical assistance by selling chemicals such as water treatment and by a joint production. Cooperation with North Korea is also considered in accordance. Meanwhile South Korea should solidify the foundation of international regime by promoting the 
Inter-Cities Cooperation Meeting (ICCM), the Environment-Development Cooperation Meeting (EDCM), and the Knowledge-Building \& Cognitive Meeting (KBCM) at the same time. As in <Figure 2>, the Yellow Sea Environment Ministers Meeting should promote to build the YSES regime by taking the BoCP as the major project and the ICCM, EDCM, and $\mathrm{KBCM}$ as a project in liaison. Those four sub-projects will be explained further in this paper.

Although the YSEMM is intended to be independent, it could also be affiliated to the Tripartite Environmental Ministers Meeting (TEMM) under the the name of ROK - DPR $\mathrm{K} \cdot$ PRC Environmental Ministers Meeting (<Figure 3 $>$ ).

$\langle$ Figure 3> The YSEMM and the TEMM

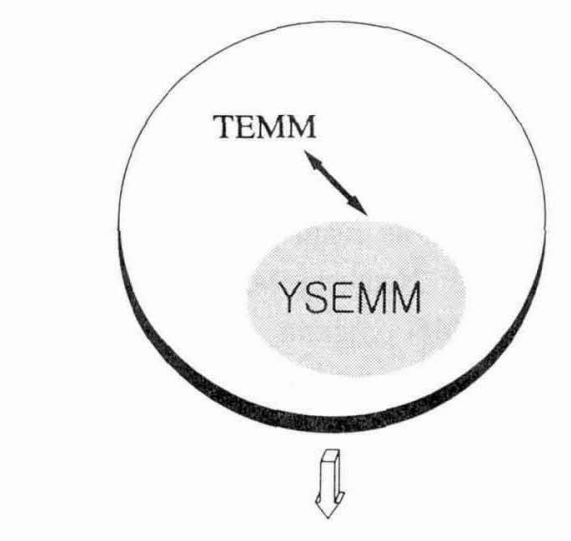

Creation of environmental regimes on various issue-areas in Northeast Asia including the YSES regime

\section{The Bohai Cooperation Project (BoCP)}

The BoCP should be formed and implemented under the auspice of the YSEMM upon the following principles:

First, it is favorable to start the first period of the $\mathrm{BoCP}$ at the end of 2005, when the 10.5 Plan of China begins, so that the BoCP can support the objectives of the 10.5 Plan. According to the 10.5 Plan, the goal for the Bohai Bay is to reduce total discharge of chemical oxygen demand (COD) into water bodies to 1.026 million tons, nitrogen and phosphorus to 130,000 tons and 10,000 tons respectively by 2005 . Besides, its main project is to build 11 sewage treatment plants in the coastal cities around the Bohai Bay and secure a centralized sewage treating capacity of 930,000 tons per day.

Second, it is desirable for South Korea to begin its cooperation with China in such fields as funding for research or human resources, providing measure-technology, and 
selling water treatment chemicals on the condition of transferring technical know-how rather than direct investment to a sewage treatment plant building.

Third, various working-level meetings must be organized for the BoCP to deal with the details of the project.

Fourth, because the World Bank and the Asia Development Bank (ADB) have already funded the Bohai Project of China, the BoCP should secure support from various international organizations, including financial aid from the $\mathrm{ADB}$ and the Economic \& Social Commission for Asia \& the Pacific (ESCAP).

Fifth, in case South Korea does not lead the BoCP, a professional person with international fame and influence can frame and manage it.

\section{The Inter-Cities Cooperation Meeting (ICCM)}

Nanyang City in Henan Province shows South Korea how to cooperate with Chinese cities for the environment. ${ }^{34)}$ Nanyang City, to effectively implement 'Local Agenda 21' (LA21), has forged friendly ties with more than 10 countries including Canada, Sweden, the United States, and Japan. One of its main projects is the collaboration with the US. The Iowa State University initiated 'Nanyang Model Project,' an important part of the Sustainable Development Henan (SDH) program, with the support of Chinese entities such as the Chinese Academy of Sciences, the Henan Provincial Science and Technology Commission. For the project, the environmental experts from the Iowa State University have visited Nanyang several times to investigate local conditions: development of eco-agriculture, clean production, treatment of waste, and urban construction. Seminars were held on regional sustainable development, environmental education, environmental cleanup, and climate change. According to a memorandum signed by the two sides, Nanyang will apply patented technologies from the US to develop a biological gasification system using crop stalks to provide fuel to farmers and improve the environmental quality. The Iowa State University has also agreed to help Nanyang College of Technology to build an environmental engineering department by training Chinese teachers and providing management expertise. In addition, the two sides agreed to advance the cooperation in eco-agriculture and clean production.

A Sino-Swedish cooperative project on LA21 was launched in 1997. In January, an international seminar was held in Nanyang, where the two sides agreed for technical cooperation. In October 1997, a Chinese government delegation and municipal officials from Nanyang visited Ulan, Sweden and signed a protocol with the city government on bilateral cooperation. In October 1998, an Ulan delegation visited Nanyang to look into its papermaking, green agriculture, pharmaceuticals, foreign trade, energy development, and other industries. This visit yielded nine letters of intent on LA21 cooperation, methane development, Chinese medicine development, and clean production. Currently, Nanyang is 
making all the necessary preparations for the implementation of those protocols.

The Nanyang case shows that the ICCM should be a place for open and unrestrained discussions among experts and leading government officials for information exchange and policy dialogue. The major relevant districts and cities are as follows: Seoul, Gyeonggi-do, Inchon (South Korea); Pyungyang, Pyungan-namdo, Hwanghae-namdo, Gaesung, Shinouijoo (North Korea); Beijing, Liaoning, Hebei, Shandong, Tianjin, Dalian, Yantai (China). Among them, the ICCM can start with Seoul, Inchon, Pyungyang, Shinouijoo, Tianjin, Dalian, and Yanta, the locations relatively near the Bohai Bay.

The Nanyang case provides additional guidelines for the ICCM: the ICCM should support the projects in the highest demand in the cities and the districts of China and North Korea; its important fields for cooperation include ecological farming, discharge of wastes, building cities, chemical development, energy development, environmental cleanup, environmental education, seminars, training programs, and technical consulting.

Like the BoCP, the ICCM also needs support from international finance organizations (e.g., World Bank, ADB) and international environmental organizations (e.g., UNEP).

\section{The Environment-Development Cooperation Meeting (EDCM)}

The EDCM is a place where major companies in countries of the YSES cooperate for the goal of sustainable development. The EDCM is necessary because the environmental preservation and improvement largely depends on economic activities of the enterprises. In the EDCM, enterprises will share pro-environmental experiences, ideas, and know-how, aiming at leading the industrial and economic development in the YSES to the pro-environmental direction.

For the success of the EDCM, environmental department of the respective government will need to motivate and support companies to participate voluntarily and actively at this meeting.

Major big businesses need to take an initiative because of their green technologies, their great impacts on environment, and their capabilities and know-hows for this kind of meetings. In South Korea, Doosan Eco-Biz Net by Doosan Group, Environment Management and Zero discharge of waste water by LG Chemical, and Eco-2000 Movement by Hanhwa Group are good examples of pro-environmental management. Environmental industries can also participate in the meeting. The Ministry of Environment of Korea, in liason with the TEMM, started the Tripartite Roundtable on Environmental Industry attended by environmental industries in those three countries (Korea, China and Japan). 35 ) This roundtable can be a model for the EDCM.

The EDCM can consider participation of not only companies in the countries bordering the Yellow Sea, but also companies from environmentally advanced countries. As for funding, governments, companies, and international organizations can raise a fund in collaboration.

35) See "Welcoming Address: the lst Tripartite Roundtable on Environmental Industry." (http://www.me.go.kr/)(2002. 10. 17). 


\section{The Knowledge-Building Cognitive Meeting (KBCM)}

The KBCM is a place for experts including scientists, government officials in charge, environmental activists, and the press in countries of the YSES countries to cooperate for the goal of sustainable development. The KBCM is grounded on the fact that 'cognitive community' is a requisite for regime formation and evolution.

Its goals are to share and deepen pro-environmental knowledges among the participants, to back up the YSEMM to have a substantial influence on their governments with accurate information and pragmatic ideas, to spread those knowledges, information, and ideas among the publics, and consequently, to help the formation and strengthening of the YSES regime.

For these purposes, the KBCM should be a place for its secretariats and task force teams to publish as well as to plan the content and the objectives of the meeting.

\section{Search of liaison with Knowledge Partnership}

The Korean Ministry of Environment and the World Bank have signed the environmental cooperation protocol to launch the Knowledge Partnership (KP) project in Asian developing countries to transfer Korea's environmental technology to them. The Ministry of Environment held the Environmental Management Workshop in December 2001 in Seoul under the agreement with the World Bank to build up a bilateral environmental cooperations with China, Vietnam, and Philippines. It also planned to promote the Haiphong Eco-City Development with Vietnam as a model of the KP project.

The KP project could be a model for the EDCM and the KBCM in seeking for what they should do in concrete: they could set their own agenda focusing on environmental progress in the Bohai Bay area, or they could connect their projects to the KP project: for the KP project already included China, its goals can introduce, for instance, the transfer of Korea's environmental technology to China to cut off the land-based pollutants in the Bohai Bay area in liaison with the EDCM. The KBCM, for its part, can co-hold seminars and workshops in liaison with the KP project.

\section{Conclusion}

As the threshold of the YSES regime, the MOSS approach in the Bohai Bay is suggested. This is because the Gulf of Thailand Project verified the efficiency of Moss approach: the gulf's serious condition addressed common threat to the member states, leading the project towards success despite the differences among the states. The Bohai Bay also has serious condition and addresses common threat to South and North Korea as well as China. The MOSS approach is viable because of China's interest in the Boahi Bay. There are two different opinions on why Chinese government is paying such a great attention to this bay. One opinion is that China has a real intention to improve its 
environmental condition. The other is that China needs the image of a pro-environmental nation to continue pursuing active industrial developmental policies. It seems realistic to say both reasons are right, which suggests that China's interest has changed into that of pro-environmental at least in the Boahi Bay. This provides South Korea the opportunity to begin its environmental cooperation in the Bohai Bay and to develop the cooperation towards the regime in the Yellow Sea, the YSES regime. Although the success of this project depends on South Korea's diplomatic capability, it is undeniable that the BoCP, the co-work in the Bohai Bay, is one of the most feasible ways to start for the environmental regime formation in the Yellow Sea sphere.

The sub-projects of the ICCM, the EDCM, and especially the KBCM are based on the theoretical finding that 'knowledge' is one of the most important factors in the issue-area of environment and in establishing a regime. Although unlikely, these meetings can be unsuccessful. Nevertheless, these meetings will still be important because the more consolidate, the more likely YSES regime emerge and evolve.

Although it is controversial if cooperation in one area can spill-over to another area, the Mediterranean Sea regime and the North Sea regime suggest that the argument is valid. As analyzed, the Mediterranean Sea regime started as the UNEP's regional cooperation programme but has evolved into a complex regime addressing broader environment and development issues. The North Sea regime has also evolved into more complex one with many revised norms and rules, as we saw in the more tightened legal control on low and medium radioactive contaminants instead of the abolition of grey/black system. Nevertheless, because China has a socialistic system and has more economic and diplomatic power than South Korea, it is unrealistic to expect a smooth evolution from the Bohai Bay cooperation to the significant Yellow Sea regime. Therefore, for the successful regime evolution, South Korea and international organizations should motivate China with incentives like the support for the Bohai Bay. 


\section{References}

Andresen, Steinar, Tora Skodvin, Arild Underdal and Jorgen Wettestad, Science and politics in international environmental regimes: Between integrity and involvement (Manchester and New York: Manchester University Press, 2000).

Andresen, Steinar, "The North Sea and Beyond: Lessons Learned," in Mark J. Valencia (ed), Maritime Regime Building: Lessons Learned and Their Relevance for Northeast Asia (The Hague/Boston/London: Martinus Nijhoff Publishers, 2001), pp. 51-72.

Caldwell, Lynton Keith, International Environmental Policy: Emergence and Dimensions, second edition (Durham and London: Duke University Press, 1990).

Chircop, Aldo, "The Mediterranean: Lessons Learned." in Mark J. Valencia (ed), Maritime Regime Building: Lessons Learned and Their Relevance for Northeast Asia (The Hague/Boston/London: Martinus Nijhoff Publishers, 2001), pp. 27-50.

Guan, Daoming, Gengchen Han, Juying Wang, "Marine Environmental Quality and Marine Environmental Protection in China," (http://www.unesco.or.kr/kor/science/d ata/Guan.doc.) (2003. 10. 17).

Haas, Peter M., "Introduction: Epistemic Communities and International Policy Coordination," in Knowledge, Power, and International Policy Coordination, special issue, International Organization 46 (winter 1992), pp. 1-36.

Haas, Peter M., Saving the Mediterranean: The Politics of International Environmental Cooperation (New York: Columbia University Press, 1990).

Harris, Paul G., "Introduction: International Environmental Cooperation in Pacific Asia," in Paul G. Harris (ed.), International Environmenatl Cooperation: Politics and Diplomacy in Pacific Asia (Boulder, Colorado: University Press of Colorado, 2002).

Johnston, Douglas M., "Southeast Asia: Lessons Learned," in Mark J. Valencia (ed), Maritime Regime Building: Lessons Learned and Their Relevance for Northeast Asia (The Hague/Boston/London: Martinus Nijhoff Publishers, 2001), pp. 73-86.

Keohane, Robert O., "The demand for international regimes," in Stephen D, Krasner (ed.), International Regimes. (Ithaca and London: Comell University Press, 1983), pp. 141-172.

Krasner, Stephen D., "Regimes and the limits of realism," in Stephen D, Krasner (ed.), International Regimes (Ithaca and London: Comell University Press, 1983), pp. 355-368.

Krasner, Stephen D., "Structural causes and regime consequences: regimes as intervening variables," in Stephen D, Krasner (ed.), International Regimes (Ithaca and London: Cornell University Press, 1983), pp. 1-21.

List, Martin and Volker Rittberger, "Regime Theory and International Environment Management," in Andrew Hurrell and Benedict Kingsbury (ed.), The International Politics of the Environment: Actors, Interests, and Institutions (Oxford: Oxford 
University Press, 1992), pp. 85-109.

Miles, Edward L., Arild Underdal and Jorgen Wettestad, Environmental Regime Effectives: Confronting Theory with Evidence (Cambridge: MIT Press, 2001). Ministry of Unification, "Analysis on 2001 North Korean Economy," (http://www.u nikorea.go.kr $/ \mathrm{kr} / \mathrm{unipds} / \mathrm{unipds}$ _publication.php?cur_page $=\& \mathrm{pdm}=\& \mathrm{pmd}=$ view\&num $=108)(2003.10 .17$.$) .$

Ministry of Unification, The North Korean Economy in 2002 and its Prospects for 2003 (http://www.unikorea.go.kr/(2003. 10. 17).

Rittberger, Volker, Jonathan Michie and John G. Smith, Regime Theory and International Relations (Oxford: Oxford University Press, 1995).

UNEP, Co-ordinated Mediterranean Pollution Monitoring and Research Programme (MEDPOL) - Phase I: Programme Description, UNEP Regional Seas Reports and Studies No. 23 (UNEP, 1984), pp. 1-16.

UNEP, Global Environment Outlook 3: Past, present and future perspectives (Sterling, VA: Earthscan Publications Ltd, 2002).

UNEP, Mediterranean Action Plan and Convention for the Protection of the Marine Environment and the Coastal Region of the Mediterranean and its Protocols (Informal Document) (Athens: UNEP, 1997), pp. 1-29.

UNEP, MEDPOL-Phase 1II: Programme for the Assessment and Control of Pollution in the Mediterranean Region (1996-2005), UNEP(OCA)/MED. WG.89/5, 15 January 1995 (Athens: UNEP, 1995).

UNEP, Report of the Intergovernmental Meeting on the Protection of the Mediterranean, Barcelona, 28 January-4 February 1975. UNEP/WG.2/5, 11 February 1975.

UNEP/MAP, Co-ordinated Mediterranean pollution monitoring and research programme (MED POL - PHASE I). Final report, 1975-1980 (UNEP/MAP, 1986) (http://62. 68.74.75/sample/Final/MTSFull.htm)(2003. 10. 17).

UNEP/MAP/FAO, Baseline studies and monitoring of metals, particularly mercury and cadmium, in marine organisms (MED POL II) (UNEP/MAP/FAO, 1986) (http://62.68.74.75/sample/Final/MTSFull.htm)(2003. 10. 17).

Valencia, Mark J. (ed), Maritime Regime Building: Lessons Learned and Their Relevance for Northeast Asia (The Hague/Boston/London: Martinus Nijhoff Publishers, 2001).

China Daily, 2003.3.30; 2003.4.1.

http://216.239.33.100/search?q=cache:v4pyK1VALRcC:www.usembassy-china.org.cn/engli $\mathrm{sh} / \mathrm{sandt} / \mathrm{estnews} 0615 \mathrm{htm}+$ bohai + bay+environment $+2001 \& \mathrm{hl}=\mathrm{en} \& \mathrm{ie}=\mathrm{UTF}-8(2002$. 10. 23).

http://www.acca21.org.cn/indexe2.html(2002. 10. 23).

http://www.acca21.org.cn/pp5-8.htlm(2002. 10. 23).

http://english.peopledaily.com.cn/200201/28/eng2002012889496.shtml(2003. 10. 17).

http://www.giwa.net/giwa_doc/giwa_matrix.pdf(2003. 10. 17).

http://www.me.go.kr/(2002. 10. 17). 


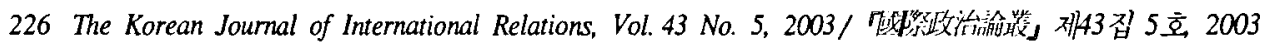

http://www.usembassy-china.org.cn/sandt/estnews0615.htm(2003. 10. 17).

http://www.zhb.gov.cn/english/SOE/soechina2000/english/marine/marine_e.htm(2003. 10. 17).

http://www.zhb.gov.cn/english/SOE/soechina2001/english/2-marine.htm(2003. 10. 17). 